\title{
LA MUERTE DE TOLSTOI EN LA PRENSA COSTARRICENSE
}

\author{
Alvaro Quesada Soto
}

\begin{abstract}
An analysis of some comments upon Tolstoi's death published in Costa Rican papers in 1910 and 1911. These publications can give us an idea about the influence that the thinking and the works of the Russian writer had in several social and cultural Costa Rican circles at the beginning of this century.
\end{abstract}

\begin{abstract}
“El gran anarquista León Tolstoi ha muerto (...) Esto ha sido Tolstoi: manso como Cristo, viril como Zola, rebelde entre los rebeldes".
\end{abstract}

ARISTIDES RODRIGUEZ. Hoja Obrera, 6 de diciembre de 1910.

"Heroico ex-Conde, tus simientes germinan aun entre el hielo de Siberia... ¡Cada día el rumor de tu siembra es más sonoro... y en alguno el rumor será rugido, y el rugido tempestad! Descansa León de paz, los soldados de tu cruzada no decaen..."

AMADO CHAVERRI. Hoja Obrera, 6 de diciembre de 1910.

En 1985 se cumplieron 75 años de la muerte de León Tolstoi, acaecida el 20 de noviembre de 1910. El silencio que rodeó esta fecha en los círculos intelectuales y académicos de nuestro país, contrasta con las múltiples muestras de dolor, admiración y respeto que suscitó la noticia de su muerte en los círculos de intelectuales, artesanos y obreros costarricenses en 1910 y 1911 . Este artículo no pretende ofrecer una recopilación exhaustiva de las publicaciones costarricenses sobre la muerte del gran novelista. Solo pretende hacer referencia, con base en algunos artículos entresacados de periódicos y revistas de la época, a las variadas respuestas que generó en nuestro país la noticia de la muerte del gran escritor y pensador ruso.

1. Afirmaba Constantino Láscaris en su obra Desarrollo de las ideas filosóficas en Costa Rica que Tolstoi "aparte de Unamuno es el escritor que más ha influido en Costa Rica" (1). Al desavisado lector contemporáneo podría extrañarle esta apreciación. Todo aquél familiarizado con las publicaciones literarias y socio-culturales costarricenses de las primeras décadas de nuestro siglo, no podría menos que reconocer la justeza de aquella afirmación. Entre los jóvenes intelectuales, periodistas y escritores costarricenses de las primeras décadas del siglo XX, la influencia de Tolstoi sólo era comparable con la de Zola, entre los novelistas europeos, o la de Rodó, Darío y Martí, entre los autores latinoamericanos. Entre los jóvenes intelectuales costarricenses de principios de siglo, las figuras de Tolstoi o Zola aparecían ligadas a ciertas ideas de reforma y renovación social, calificadas indistintamente por ellos mismos como "libertarias", "socialistas", "acratas" o "anarquistas" (2). Esas concepciones "anarquistas" acercaban a estos escritores a las luchas y preocupaciones de los grupos artesanoobreros que comenzaban a organizarse en las ciudades (sobre todo en San José) en busca de reformas económicas, sociales y políticas, que les garantizaran mejores salarios y una vida más digna, más sana y más justa. Esas concepciones los separaban al mismo tiempo de las ideas "liberales" de los viejos intelectuales oligárquicos de la llamada "generación de 1889" o "generación del Olimpo" (3).

Para entender el especial ascendiente de Tolstoi sobre estos jóvenes intelectuales, y para comprender su original manera de interpretar el pensamiento y la obra del "gran anarquista León Tolstoi", creemos necesario iniciar nuestro trabajo con esta breve referencia al peculiar contexto histórco e ideológico donde se gestaron las ideas "acratas" o "anarco-socialistas" costarricenses de las primeras décadas del siglo XX.

Si bien los términos "anarquismo", "socialismo" o "comunismo", al igual que "proletarios" y "obreros", formaban parte - como se verá en las citas 
que habremos de reproducir más adelante - del discurso político-cultural costarricense de aquellos años, los contenidos y el significado concreto de estos términos no coincidían en su totalidad con los tradicionales en el pensamiento europeo. En la Costa Rica de principios de siglo, los primeros sentimientos de protesta contra el sistema de relaciones económicas y sociales establecido, comenzaban a hacerse sentir en los núcleos urbanos, por parte de artesanos amenazados por la incipiente industria o los productos industriales importados por antiguos campesinos expropiados o desplazados en busca de cualquier oficio; por los empleados públicos o un incipiente proletariado urbano; por aquellos grupos que Cleto González Víquez denominaba pintorescamente "proletarios de levita" (4).

Con ellos se identificaba un grupo de maestros, escritores e intelectuales pequeño burgueses más o menos radicalizado. Pero estas ideas surgían en un medio donde dominaba un capitalismo agrario y dependiente, donde no se había iniciado un proceso de industrialización y apenas se desarrollaba, lenta y paulatinamente, la proletarización del campesino. Los valores de cambio no regían la totalidad de la vida social, la división del trabajo estaba escasamente fragmentada y la conciencia de la alienación del hombre con respecto a la vida social o con respecto a su propia actividad, no era tan radical como en los países industrializados.

De aquí que la rebeldía de estos grupos se rigiera por criterios más bien reformistas o evolucionistas, orientados al logro de mejoras en la condición de vida y las circunstancias laborales de los trabajadores; pero que no procuraban una revolución que tuviera como objetivo la toma del poder por los trabajadores, o el empleo de la violencia como medio para transformar las relaciones políticas, económicas y sociales establecidas (5). Las ideas de los intelectuales "anarquistas" o "socialistas" costarricenses de estos años, más que por un análisis científico de los factores históricos, económi$\cos$ y sociales que determinaban la exploración o la desigualdad en las relaciones sociales, se regían por criterios de adhesión sentimiental o intelectual hacia los que sufren, o hacia las víctimas de la explotación, la crueldad o la injusticia.

De aquí que en sus representaciones ideológicas - como en el pensamiento de Tolstoi (6) - pudiera conjugarse la idea de una "revolución social", de una denuncia de las instituciones, discursos y prácticas sociales, políticas y religiosas establecidas, con la prédica cristiana de amor y respeto al próji- mo, y el llamado a "no combatir el mal con la violencia". En las representaciones de nuestros jóvenes "acratas" de principios de siglo, "anarquismo" y "socialismo", "cristianismo" tolstoyano e "idealismo" arielista (7), no eran concepciones ideologías contrarias o excluyentes, eran ideologías concomitantes que se oponían al "egoísmo "y al "utilitarismo" liberal-burgués: a la conversión de las relaciones humanas en valores de cambio mercantiles, cuya validez habría de determinarse según la cantidad de dinero o el provecho individual que aportasen. En un documento autobiográfico escrito poco antes de su muerte, uno de estos jóvenes radicales de principios de siglo, la escritora Carmen Lyra - quien en 1931 ingresaría al recién fundado Partido Comunista de Costa Rica- evocaba así los impulsos que guiaron la "rebelión romántica" de su primera juventud:

"Era una criatura que vivía emocionada en la superficie del espacio y del tiempo y su pensamiento giraba como una mariposa loca alrededor de una llama. El mejor guía de la juventud inquieta de Costa Rica en aquellos días era José Enrique Rodó con su Ariel y sus Motivos de Proteo... por aquel tiempo mi sed de justicia sabía aplicarse con el gesto misericordioso del obispo de Los miserables, quien ofrece al ladrón - para defenderlo - sus candelabros de plata cuando los gendarmes lo traen ante el bondadoso prelado con los cubiertos que Jean Valjean había robado. Este gesto del personaje de Víctor Hugo se entendía muy bien dentro de mi conciencia de entonces con la no resistencia al mal de Tolstoi y con la rebeldía de los personajes de Zola" (8).

2. El 10 de noviembre de 1910 (28 de octubre según el antiguo calendario ruso) a las 3 de la madrugada, León Tolstoi abandonó en secreto su casa en la hacienda de Yasnaia Poliana y se dirigió al Monasterio de Shamardino en donde profesaba su hermana María Nicolayevna. En la carta que le dejó a su esposa Sofía Andreyevna entre otras cosas le decía:

"Mi marcha te afligirá y lo siento, pero compréndeme y créeme que no podía conducirme de otra manera. Mi situación en casa se ha vuelto intolerable. Además de muchas otras cosas, no puedo seguir viviendo en las condiciones de lujo en que he vivido siempre, y voy a hacer lo que hacen habitualmente los ancianos de mi edad; abandonar la vida mundana, para vivir en soledad y en silencio los últimos días de su vida. Te lo ruego, comprende esto y no vengas a buscarme, ni trates de averiguar donde estoy..."

El 13 de noviembre escribió a su hermana María en el Monasterio: "Nos marchamos de improviso porque temo que Sofía Andreyevna me encuentre aquî". Y bajo un temporal inclemente, el anciano 
de 82 años abandona el Monasterio con el propósito de dirigirse en tren hacia el Cáucaso o traspasar la frontera rusa para instalarse en Bulgaria, donde pudiera llevar la vida de cualquier campesino anónimo. En un vagón de tercera clase del ferrocarril Riazán-Ural, Tolstoi inicia el largo viaje que se vería interrumpido por la enfermedad a la altura de la pequeña estación de Astápovo. Allí, en la casa del jefe de la estación, murió el anciano escritor a las seis de la mañana del 20 de noviembre de 1910. El 22 de noviembre fue enterrado - según su voluntad expresa - en el bosque de Yasnaia Poliana, en el mismo lugar donde en su infancia jugaba con su hermano a encontrar la "ramita verde", que habría de garantizar la hermandad y la felicidad para todos los hombres (9).

El 27 de noviembre de 1910, una de las principales revistas literarias y culturales costarricenses de la época, Páginas Ilustradas, publicó un comentario de Roberto Valladares a las primeras noticias que se recibieron en el país sobre los hechos que rodearon la muerte del gran escritor ruso (10). El artículo estaba dividido en dos partes, que eran sendos comentarios a dos aspectos de la noticia colocados como epígrafes de cada una de las partes. El epígrafe de la primera parte decía: "Tolstoi ha desaparecido y se ignora su paradero" (en realidad Tolstoi había muerto una semana antes de la fecha de publicación de la revista). Valladares comentaba:

"León Tolstoi ha desaparecido; el mujik que enseñaba el bien a los esclavos rusos en sus libros de bondad nazarena, se ha perdido! El maestro cariñoso y amado que educaba a los niños de su escuela Yasnaia Poliana, huyó dejando el vacío inevitable en su escuela y en desconsuelo a sus pequeños discípulos. Los suyos, sus amigos y sus familiares le buscan inconsolables, es una noticia de sensación en Rusia la de su fuga, hasta el gobierno mismo le busca; y los que quisieran verle muerto, se interesan por su vida.

Es que León Tolstoi no es un ruso, el conde Tolstoi es un ser de lujo en el mundo, es una joya de todos los países y de todos los hombres(...)

..Al cabo se asegura haber descubierto su paradero. El Conde se ha refugiado en el Monasterio de Scamardink [sic], pero no quiere ver a nadie ni permite que le vean (...) Y entre tanto el cable lleva al alma de todo el mundo la nueva, e inmediatamente los hombres exclaman: "está loco"! y se pregona la demencia sin que haya un sabio, un psiquiatra, un alienista que en esta vida turbulenta limite la locura de los cuerdos ni señale la cordura de tanto loco..."

La segunda parte lleva el siguiente epígrafe: "Se asegura que Tolstoi está demente en el Monasterio de Scamardink". Aseveración que sirve a Valladares para divagar sobre el tema del genio y la locura, y para establecer paralelos entre la "locura" de Tolstoi y la "locura" de Jesús, Maupassant, Baudelaire o Nietzche:

“Tú también - venerable león encanecido, dulce mujik de las estepas del septentrión - debías rendir el alto tributo de tu razón a la Locura(...)

Tu nombre que repiten ahora los labios de los hombres todos, en todas las lenguas emitidas, ha sido inscrito en el catálogo glorioso de los inmortales dementes sobre cuyos hombros descansa la Historia del Universo: Jesús el nazareno, el más loco; Galileo el sublime perseguido, Cristóforo Colombo, atacado de locura marina y de la pesadilla de los mundos desconocidos; y tras 'estos y otros locos de leyenda que vivieron en el mundo niño, los admirables locos del asilo y de la camisa de fuerza (...)

Divinos locos, recordémoslos [sic]...! Este: Guido de Maupassant el más sutil y agradable conteur de Francia (...) Este otro: Baudelaire, diabólico y extraño rebuscador de emociones desconocidas en los artificiales paraísos del placer... Y éste, fuerte varón, de frente altiva y de mirada agresiva, y de facciones duramente cemiescas [sic]... éste es el loco de acero el exéjeta [sic] iracundo, el filósofo envenenador de la época... Bajó a las oscuras cavernas donde las fieras y las sierpes enseñaron a Zaratustra los cánones de una vida superior, y cuando el morador de aquellos abismos le enseñara la clave de su sabiduría superhumana, volvió a los hombres, fue el anticristo audaz, hirió de muerte a una fe caduca y predicó la soberbia y la rebelión, la fuerza única triunfadora, y la venganza impiadosa: negó los bienes ultraterrestres, aconsejó que cien bofetadas respondiesen al agresor de una y proclamó la suprema altivez del YO, su defensa y conservación, su perfección y embellecimiento, y modeló con una arcilla desconocida, extraída de las cabernas [sic] zaratustranas el boceto del superhombre que el alma nueva, en marcha hacia la meta de una perfección altiva y orgullosa, - vaciará en el molde del futuro-. - Este grande asilado, simiesco y altanero que murió luchando contra la fuerza de su camisa; este loco violento te antecede; ;ya que para las ironías sangrientas y para las antinomias [sic] de la suerte es la vida multiforme! y en el catálogo de la Locura leerán los hombres futuros juntos el venerado nombre tuyo, y el extigmatizado [sic]! nombre del loco germano.

Oh! y quien lo pudiese preveér [sic] ¿Serán los seres que lean ambos nombres, dulces y mansos como los corderos pascuales, los hombres perdonadores y cristianos que tú sueñas, oh viejo moscovita, o serán los altaneros, impiadosos superhombres nieztcheanos $[\mathrm{sic}]$ ?

Terminaba el artículo con las siguientes reflexiones:

"No hay quien conteste afirmativa o negativamente; sin embargo, bien triste ha de ser para tí, anciano predicador, la visión que ante tus ojos extienden el mal triunfante, la guerra agostadora, la envidia venenosa y la soberbia hiriente, y en el desierto de una vida de labor tenaz, el estéril riego de tu simiente inútil... Acaso esta visión desconsolable, y el tiempo que sobre tu vigorosa humanidad ha hincado las garras del cansancio, te impelen al retiro y a la meditación última.

Loco, místico demente, o sabio filósofo, tu gloria es la misma! Si cansado, que el claustro y su sedante soledad te amparen, y si desencantado, si muertas tus esperanzas todas, 
que en el sereno jardín de tu meditar intenso florezcan todas las rosas de una ilusión postrera, de una esperanza senil que te acompañe hasta la tierra cariñosa cuando ella, que tanto amabas, te dé blando y eterno lecho"

3. El 6 de diciembre de 1910 - a dos semanas de la muerte de Tolstoi- el periódico Hoja Obrera, que se proclamaba "Organo de la Sociedad de Trabajadores" y "Defensor de los derechos del pueblo", editado por Octavio Montero y Amado Chaverri, artesanos de amplia trayectoria en las luchas sociales de la Costa Rica de principios de siglo, publicó una serie de artículos en homenaje a la memoria de Tolstoi. Los artículos publicados en Hoja Obrera son una buena muestra de la manera cómo se leía a Tolstoi en los círculos artesanoobreros costarricenses de la época. En el artículo inicial Aristides Rodríguez (11), después de anunciar que "el anarquista León Tolstoi ha muerto", comparaba las ideas de Tolstoi con las ideas anarquistas:

"Los anarquistas que esperan por la fuerza la realización de sus ideas rechazan las de Tolstoi (por la persuación) aunque marchan de acuerdo en lo que se refiere a condenar las instituciones de ejército, gobierno, tribunales, impuestos, etc. etc.".

A continuación señalaba el articulista aquellos puntos del ideario de Tolstoi que lo acercaban a las ideas anarco-socialistas:

"LA GUERRA, dice: es ir a matar hermanos con hermanos, por el capricho de un tirano o por un pedazo más de tierra.

EL PATRIOTISMO es un sentimiento útil solamente a los gobiernos... es la servil sumisión a los gobernantes, el patriotismo es la esclavitud desde luego que nuestra patria es el mundo (...)

De LA PROPIEDAD dice: origina un dominio de los poseedores, sobre los no poseedores. El mundo es de todos y para todos, no es de unos pocos.

EL ESTADO es un ídolo... El gobierno es dentro de él, una reunión de hombres que ejercen violencia sobre los demás...

Tolstoi ha sido grande entre los grandes, es uno de los pocos que ha unido a la palabra, la acción... Esto ha sido Tolstoi: manso como Cristo, viril como Zola, rebelde entre los rebeldes".

En otro de los artículos, Octavio Montero (12) ponía énfasis en el humanismo crítico que enlazaba el "apostolado" y la "rebelión", la "palabra" y la "acción", en la obra y el ejemplo de Tolstoi:

"Con su pluma sentimental pintó los dolores humanos; con su pluma virtuosa cantó paz y amor: con su pluma rebelde anatematizó los poderes constituidos... Su apostolado lo aparejó con la práctica; enseñaba con la palabra y ratificaba con el ejemplo (...)

Cada obra suya es un sólido cimiento en que descansara una futura organización social creada en un ambiente más purificado.
También este gran apóstol tenía sus justas rebeldías, producto de su sinceridad, al comprender con dolor que el bien al hermano encontraba la fuerza opositora de las tiranías ahogadoras que aplastan todo noble esfuerzo de reivindicación... No es solamente para la Rusia oprimida la tristeza por la desaparición de Tolstoi, es para el mundo entero".

Otro de los editores del periódico, Amado Chaverri (13) ponía también énfasis en esos mismos aspectos al enaltecer la importancia universal de la figura y la obra de Tolstoi:

"Viejo bárbaro! En este siglo rojo, en el "atiliaco" siglo de las revoluciones... aparece este manso León con una bandera blanca en la garra compasiva y pasa predicando su evangelio de paz por entre los miserables poderosos que amazan [sic] el pan de la burguesía, a cambio de la corteza dura que ella les deja en la mesa del festín! - Y pasó con su bandera blanca, gloriosa con sus locuras de apóstol.

Comprendió la injusticia del blasón, quebró el escudo, despedazó la librea para meter sus pies en la humilde sandalia del aldeano e ir como él tropezando en las pi edras del camino. Heroico ex-Conde, tus simientes germinan, aun entre el hielo de Siberia... ¡Cada día el rumor de su siembra es más sonoro... y en alguno el rumor será rugido, y el rugido tempestad! Descansa León de paz, los soldados de tu cruzada no decaen: tu muerte - en el campo- los enardece y van impertérritos al asalto. -Descansa [sic]!"

Finalmente, Juan de Dios López (14) señalaba en otro artículo la cercanía de las ideas del Conde Tolstoi a las aspiraciones y luchas populares:

"Sus principios eran la humanidad, igualdad su ley y la redención su ideal. Tolstoy ha sido el defensor más valiente, sabio y grande de la causa de los pueblos. Nació únicamente para salvar a los hijos de su Patria, la Rusia, de la cruel opresión... haciéndoles comprender con sus sabias enseñanzas las ambiciones desapoderadas, inicuas y brutales de su gobierno... Pero esas doctrinas tan verdaderas, nacidas de un corazón que vivió entre los grandes, respirando el ambiente monárquico y que bajó a confundirse con el pueblo, tuvieron que esparcirse por todos los ámbitos del globo, como un verdadero lema de salvación.

El duelo es mundial, pero lo participaremos más sinceros nosotros los obreros, la clase proletaria, los que sufrimos sobre nuestras espaldas la gran carga del Estado, la Aristocracia y el Clero... Pero no porque hayamos perdido nuestro guía, nuestro padre, nuestro consejero y nuestra palanca, debemos desmayar... Todos unidos con vigor, con los ideales y doctrinas de nuestro redentor León Tolstoi como estandarte, nos haremos respetar".

Este mismo periódico reproducía también la siguiente noticia, tomada según se indica ahí "de $E l$ Noticiero:

"SERMON SOBRE LEON TOLSTOY: En el sermón pronunciado el domingo anterior en la iglesia de Mata Redonda, el Presbítero doctor don Jorge Volio hizo el panegírico de León Tolstoy. El señor Volio recomendó a sus feligreses orar por el alma de Tolstoy, en atención a los sentimientos caritativos que 
adornaron al ilustre difunto... El doctor Volio manifestó su admiración por Tolstoy, por el talento, ilustración, y sobre todo, por lo humanitario, cualidades que siempre brillaron en aquel varón".

La admiración del joven Padre Volio - figura excepcional en la historia de Costa Rica, quien poco más tarde se convertiría en General Volio luchando contra el ejército invasor de los Estados Unidos en Nicaragua, después en fundador del Partido Reformista y luego en Vicepresidente de la República, más tarde en el primer Decano de la Facultad de Filosofía y Letras de la flamante Universidad de Costa Rica, para acabar finalmente en agricultor desengañado - por León Tolstoi, le costó un primer enfrentamiento con el Obispo Stork, quien consideraba la influencia del escritor ruso "nefasta por sus tendencias al anarquismo, nihilismo y modernismo", así como "poco conforme con las prescripciones de la Santa Sede" (15).

3. El 15 de enero de 1911 (a escasos dos meses de la muerte de Tolstoi) apareció en San José el primer número de la revista "ácrata" Renovación.

Como directores de la revista figuraban el poeta José María Zeledón - autor de la letra del Himno Nacional de Costa Rica y autor de un soneto a Tolstoi (16) - y el español Anselmo Lorenzo al que la redacción de la revista presentaba como "uno de los fundadores de la sección española de la Asociación Internacional de los Trabajadores, que desde 1868 hasta la fecha figura en el núcleo del proletariado intelectual" (17). Este primer número de la revista ofrecía a sus lectores un artículo, traducido por Joaquín García Monge, del "viejo León ruso que acaba de rendir a la muerte, intacta y brillante su energía batalladora". El artículo titulado El derecho y sus mentiras pertenecía, según nota de la redacción "a la obra realizada en su último año de vida", y ponía muy en evidencia las ideas de Tolstoi que lo acercaban al "anarquismo" y al "socialismo" de los jóvenes radicales costarricenses. Reproducimos algunos de sus párrafos:

\footnotetext{
"Se llama "derecho" para los detentadores del poder, el permiso que a sí mismos se dan de obligar a sus súbditos a hacer lo que conviene a los privilegiados... El derecho político es el derecho de quitar a los hombres el fruto de su trabajo, de mandarlos a cometer ese asesinato colectivo que se llama la guerra... El derecho civil es el derecho de unos a la posesión de miles y miles de manzanas de tierra y de los instrumentos de trabajo: y para los que no tienen ni éstos ni aquéllas, es el derecho de vender su trabajo y su vida, muriéndose de hambre, a los terratenientes y capitalistas (...)
}

El asunto es bien sencillo. Hay violadores y sus víctimas y los primeros quieren justificar sus violencias. Entonces llaman leyes las disposiciones mediante las cuales, en cierto momento, intentan ejercer su violencia sobre los otros; y el permiso que a sí mismos se otorgan para cometer esta violencia y las prescripciones a los oprimidos para que no hagan lo que les está prohibido, es lo que llaman el derecho (...)

¡La importancia educadora del Derecho! Hablar en nuestros días de la importancia educadora del derecho, es lo mismo que si se hablara (antes se hacía) de la importancia ética y educatriz, para los esclavos, del poder de los amos. Yo no sé si existe otro caso en que el impudor, la mentira y la estupidez humanas hayan alcanzado un nivel semejante..." (18).

El segundo número de la revista Renovación incluía un artículo de Solón Núñez titulado Jesús y Tolstoi, que expresaba con claridad la manera como se enlazaban, en las representaciones ideológicas de los jóvenes "ácratas" costarricenses, las ideas "cristianas", "tolstoyanas" y "socialistas":

"Jesús de Nazareth... era un socialista convencido, sincero y valiente... El socialista Proudhon, cuando formula sus doctrinas acerca de la propiedad, no hace otra cosa que inspirarse en el socialista Jesús y en el grupo de socialistas que a éste siguieron. Es acaso más atrevida la fórmula del economista francés que la de San Ambrosio, cuando dice: "El derecho privado nació de la usurpación"? (...)

El joven luchador de Galilea y el viejo luchador de Rusia tienen gran parecido... uno y otro sueñan en un día en que el egoísmo ceda el paso al altruismo... en que el odio ceda el paso al amor(...)

Sincero como Jesús, Tolstoi acompaña la acción a la palabra... comprende como Jesús que la riqueza y el lujo exagerados son la causa de la corrupción social, y predica la fraternidad y la sencillez, siendo él el primero en desprenderse de sus propiedades en beneficio de los desheredados (...)

Tolstoi debe haber muerto satisfecho de su obra; el edificio de la autocracia rusa está agujereado; su completa ruina es obra del tiempo y de la perseverancia. El, como Jesús, deja una Biblia donde inspirarse los enamorados del bien y la libertad: la Biblia de Tolstoi se compone de dos tomos: Ana Karenina y La paz y la guera [sic]" (19).

4. Este estudio sobre la repercusión de la muerte de Tolstoi en la prensa costarricense está lejos de ser completo y exhaustivo. Con él solo pretendíamos dos cosas: ofrecer (aunque tardíamente) un homenaje conmemorativo al gran escritor ruso al cumplirse los 75 años de su muerte; y poner énfasis en algunos aspectos poco destacados de la historia cultural costarricense. El historiador Mario Oliva había señalado ya en algunas de sus publicaciones (20) la influencia de varios escritores europeos y rusos -Zola, Víctor Hugo, Balzac, Tolstoi, Dostoyevski, Gorki, entre otros - en la formación de una conciencia social entre los jóvenes intelectuales y los trabajadores urbanos costa- 
rricenses, en los bordes del cambio de siglo. Nos sentiríamos muy satisfechos si este artículo pudiera considerarse un aporte a ese ingente y necesario esfuerzo por rescatar y aclarar los orígenes de la cultura y el pensamiento costarricenses, en sus complejas relaciones con el pensamiento y la cultura de otras partes del mundo.

\section{NOTAS}

(1) Constantino Láscaris, Desarrollo de las ideas filosóficas en Costa Rica, Ed. Costa Rica, San José, 1964, p. 251.

(2) Uno de los más importantes e influyentes escritores jóvenes de la época, Joaquín García Monge, recordando sus años de estudio en Chile al comenzar el siglo, afirmaba: "En Chile fortifiqué hasta la fecha el impulso contra todos los atropellos al bien, la verdad, la libertad y la justicia. Me tenían entonces por anarquista (la juventud de Chile y de nuestra América estaba por esos años bajo las influencias libertarias de Zola y de Tolstoi)", Joaquín García Monge, Obras Escogidas, EDUCA, San José, 1974, p. 20. Ese mismo autor afirmaba también: "En 1900 publiqué tres novelitas: El Moto (de factura perediana) Las hijas del campo (inspirada en las de Zola) Abnegación (inspirada en Tolstoi, Resurrección)", García Monge, op. cit., p. 23.

(3) Para un panorama más amplio de las luchas y enfrentamientos sociales e ideológico-culturales de esta época, ver: Vladimir de la Cruz, Las luchas sociales en Costa Rica (1980) y Los mártires de Chicago y el 1 de mayo de 1913 (1985): Carlos Luis Fallas Monge, El movimiento obrero en Costa Rica (1830-1902) (1983); Mario Oliva, Artesanos y obreros costarricenses (1985), "La novela y los trabajadores" y "La novela y su influencia en el movimiento popular costarricense", en Aportes (1985); Víctor Hugo Acuña, Los orígenes de la clase obrera en Costa Rica: las huelgas de 1920 por la jornada de ocho horas (1986), Gerardo Morales "Cultura nacional popular e intelectuales", en Memoria y cultura popular costarricenses (1986); Centro de Capacitación para el Desarrollo. Historia gráfica de las luchas populares en Costa Rica (1870-1930) (1986). Por haber tratado estos temas con más amplitud en otras publicaciones, nos excusamos de desarrollarlos aquí más ampliamente. Remitimos a los lectores interesados a esas otras publicaciones nuestras: "Los jóvenes ácratas, los viejos liberales y el movimiento obrero en Costa Rica (19001914)", Revista de Filología y Lingüística de la Universidad de Costa Rica, Vol. XII, N. 1, 1986, p. 191; "Transformaciones ideológicas en el período 1900-1920", Revista de Historia (en publicación): el libro La formación de la narrativa nacional costarricense (1890-1910), (1986) y el libro $L a$ voz desgarrada, que publicará próximamente la Editorial de la Universidad de Costa Rica. En las líneas que siguen procuraremos únicamente entresacar algunas ideas allí expresadas, que pudieran aclarar el contexto histórico-social e ideológico costarricense de donde surgieron las variadas reacciones y respuestas ante la muerte de Tolstoi, que se reproducen en este trabajo.
(4) Se refería el expresidente a "la precaria situación de aquellas clases sociales superiores en cultura y en pretensiones, pero carentes de fortuna, que constituye el proletariado de levita", Discurso en el Congreso el 21 de noviembre de 1916, en El pensamiento liberal, p. 318. Destacado nuestro.

(5) Sobre el "anarquismo" costarricense, afirmaba Láscaris: "Es de señalar una característica peculiar del anarquismo en Costa Rica: su pacifismo... Así, no se dio, como en tantos países, la exacervación explosiva del anarquismo, sino que este se mantuvo dentro de la línea tolstoyana", Láscaris. Desarrollo de las ideas filosóficas en Costa Rica, p. 249 .

(6) Así resumía Tolstoi su credo político en 1896: "Debe desaparecer el régimen basado en la competencia para transformarse en un régimen comunista; debe desaparecer el régimen capitalista para dar paso a un régimen socialista; ...debe desaparecer la represión y la violencia para dar paso a la libertad y el amor solidarios entre los hombres". Cit. en Russkie pisateli, Moscú, 1971, p. 634. La traducción es nuestra.

(7) José María Zeledón, por ejemplo, uno de los introductores y propagandistas del "anarquismo" costarricense de principios de siglo, fundador y director de la revista "ácrata" Renovación en 1911, era también - además de autor de la letra del Himno Nacional - autor de un soneto a Tolstoi, de un Canto a Zola, de un Manifiesto a los trabajadores del ideal y de un poema a Jesús. Este último terminaba con los siguientes versos:

"No fue infecunda, pues no fue ilusoria, tu sana y racional filosofía

que ha quedado triunfante en la memoria de los hombres; tu heroica rebeldía nos lleva, como estrella migratoria, hacia el naciente ideal de la anarquía".

Ver: José María Zeledón (Billo). Presentado por Victoria Garrón de Doryan (1978), p. 81 y 82; y J.M. Zeledón, Poesía y prosa escogida. Prólogo y selección de Alfonso Chase (1979), p. 40, 78 y 157.

(8) Carmen Lyra, Relatos escogidos, p. 437-438.

(9) Los datos biográficos han sido tomados del escrito de la hija de Tolstoi, Tatiana Lvovna, sobre la muerte de su padre en el libro: T.L. Sujotina-Tolstaya, Vospominanva (Memorias), Moscú, 1976, p. 369; y del "Prólogo biográfico de Irene y Laura Andrescu a la edición española de L.N. Tolstoi, Obras. tomo I, Aguilar, Madrid, 1973.

(10) Roberto Valladares, "El Conde León Tolstoi", en Páginas Ilustradas, año 7, No. 260, 27 de noviembre de 1910, p. 2-3. Las mayúsculas y los destacados que aparecen en los fragmentos que citaremos, pertenecen todos al original.

Roberto Valladares, "poeta bohemio" según se le define en las publicaciones de principios de siglo, nació en 1883 y murió trágicamente en 1920 , víctima de un balazo disparado accidentalmente por su hermano. En 1908 había publicado un tomo de poesía, Flauta ingenua, "que provocó un gran revuelo en el país” según afirma Rogelio 
Sotela. En las revistas de las dos primeras décadas del siglo aparecen varios fragmentos y esbozos de obras dramáticas "simbolistas", así como comentarios y críticas literarias suyas. Casi ignorado por la historiografía literaria costarricense actual (ni la Historia de la literatura costarricense de A. Bonilla ni la Evolución de la poesía costarricense de A. Baeza Flores lo mencionan) fue, sin embargo, en su época una figura innovadora atrayente y respetada, a juzgar por los testimonios de sus contemporáneos. "Era muy pobre - afirma Gonzalo Chacón Trejos - ... Fue tipógrafo como su padre, y frente al chibalote, dándole al componedor... descubrió la Poesía y ya no quiso ser otra cosa que poeta" (G. Chacón T., "Roberto Valladares" en Brecha, 1. 9, 1957, p. 9). En un artículo publicado a raíz de su muerte en 1920, Rogelio Sotela dividía su vida en dos épocas: la del "bohemio" y la del "hombre de acción". En su primera época, "temperamento exquisito, nervioso, hiperestésico, fue él quien en Costa Rica pudo y supo vivir una 'bohemia' sincera y admirable... Recluido siempre, apartado en la soledad de su romanticismo idealista, casi esquivó por muchos años la amistad de los hombres" (R. Sotela, "Roberto Valladares" en Athenea, IV, 8, 1920, p. 979). En su segunda época, "comienza a transformarse el bohemio incorregible en hombre de acción. Preocupado por las cuestiones obreras, había dado - como siempre lo hizotodo su corazón a la empresa redentora de las clases trabajadoras. Fundó la Federación Gráfica Costarricen$s e$, que ya tiene vida estable, y echó los cimientos a esa otra gran obra que ha de evolucionar en los destinos de la nación: La Universidad Obrera. Entonces es cuando aparece el signo inflexible de la muerte..." (Sotela, p. 979). (Los datos sobre Valladares fueron obtenidos en el curso de una investigación sobre el teatro costarricense de 1890-1930, en la que participó el autor de este artículo junto con los profesores Flora Ovares, Margarita Rojas, Carlos Santander y el asistente Jorge Caro).

(11) Arístides Rodríguez, "Tolstoi", Hoja Obrera, No. 61. 6 de diciembre de 1910. Mayúsculas y destacado del original.

(12) Octavio Montero, "Tolstoi", Hoja Obrera, 6 de diciembre de 1910 .

(13) Amado Chaverri, "Banderas y abanderados", Hoja Obre$r a, 6$ de diciembre de 1910. Destacado del original.

(14) Juan de Dios López, "La corona más humilde a Tolstoi", Hoja Obrera, 6 de diciembre de 1910.

(15) Ver: Marina Volio, Jorge Volio y el Partido Reformista, p. 33 .

(16) El soneto, dedicado a Joaquín García Monge, fue publicado en Páginas Ilustradas en 1904, e incluido más tarde en su libro Musa Nueva (1907). El texto es el siguiente:

"Nunca el dolor su corazón abate ni el cansancio sus ánimos doblega; altivo luchador, nunca se entrega rendido sobre el campo del combate.

En tanto que el error muerda y maltrate la humanidad atolondrada y ciega, no ha de cejar en la constante brega el sueño de paz que en su alma late.

Brillan en torno a su cabeza cana sus ardientes anhelos fugitivos con el fulgor de la ilusión cristiana, y lanza sus acentos persuasivos buscando entre la alegre fiesta humana la triste procesión de los cautivos".

Ver: José María Zeledón (Billo) (1978), p. 82 y 126.

(17) Renovación, año I, No. 1, 15 de enero de 1911, p. 3.

(18) León Tolstoi: "El derecho y sus mentiras", en Renovación, año I, No. 1, 15 de enero de 1911, p. 5-6.

(19) Solón Núñez, "Jesús y Tolstoi” en Renovación, año I, No. 2, 30 de enero de 1911, p. 23-25.

(20) Mario Oliva, "La novela y los trabajadores" y "La novela y su influencia en el movimiento popular costarricense" en Aportes, Nos. 25 y 26-27, 1985. Ver también su libro Artesanos y obreros costarricenses (1985).

\section{BIBLIOGRAFIA}

Acuña Víctor Hugo, Los orígenes de la clase obrera en Costa Rica: las huelgas de 1920 por la jornada de ocho horas, CENAP-CEPAS, San José, 1986.

Centro de Capacitación para el desarrollo, Historia gráfica de las luchas populares en Costa Rica (1870-1930), Ed. Porvenir, San José, 1986.

Chacón Trejos Gonzalo, "Roberto Valladares", en Brecha, año 1, No. 9, 1957, p. 9-10.

Chaverri Amado. "Banderas y abanderados", en Hoja Obrera, No. 61, 6 de diciembre de 1911.

De la Cruz Vladimir, Las luchas sociales en Costa Rica, Ed. Costa Rica-Ed. Universidad de Costa Rica, San José, 1980.

.Los mártires de Chicago y el 1 de mayo de 1913, Ed. Costa Rica, San José, 1985.

\section{.El pensamiento liberal, Ed. Costa}

Rica, San José, 1979.

Fallas Monge Carlos Luis, El movimiento obrero en Costa Rica (1830-1902), EUNED, San José, 1983.

García Monge, Obras escogidas, EDUCA, San José, 1974. 
Lyra Carmen, Relatos escogidos, Ed. Costa Rica, San José, 1977.

Láscaris Constantino, Desarrollo de las ideas filosóficas en Costa Rica, Ed. Costa Rica, San José, 1964.

López Juan de Dios. "La corona más humilde a Tolstoy", en Hoja Obrera, No. 61, 6 de diciembre de 1910 .

Montero Octavio, "Tolstoy", Hoja Obrera, 6 de diciembre de 1910.

Morales Gerardo, "Cultura nacional-popular e intelectuales", en Memoria y cultura popular costarricense, CENAP, San José, 1986, p. 108.

Núñez Solón, “Jesús y Tolstoi”, Renovación, año I, No. 2, 30 de enero de 1911.

Oliva Medina Mario, Artesanos y obreros costarricenses, Editorial Costa Rica, San José, 1985.

Aportes, No. 25, 1985.

"La novela y su influencia en el movimiento popular costarricense", en Aportes, No. 26-27, 1985.
Rodríguez Arístides, "Tolstoy", Hoja Obrera, 6 de diciembre de 1910.

Russkie pisatelli, Moscú, 1971.

Sotela Rogelio, "Roberto Valladares", en Athenea, T. IV, No. 8, 1920, p. 979.

Sujotina-Tolstaya T. L., Vospominanya, Moscú, 1976.

Tolstoi L. N., Obras, tomo I, Aguilar, Madrid, 1973.

."El derecho y sus mentiras", en $R \boldsymbol{e}$ novación, año I, No. 1, 15 de enero de 1911.

Valladares Roberto, "El Conde León Tolstoi”, en Páginas Ilustradas, año 7, No. 260, 27 de noviembre de 1910 , p. 2-3.

Volio Marina, Jorge Volio y el Partido Reformista, Ed. Costa Rica, San José, 1972.

Zeledón José María, José María Zeledón (Billo). Presentado por Victoria Garrón de Doryart. Ministerio de Cultura, San José, 1978.

.Poesía y prosa escogida (Selección y prólogo de Alfonso Chase), Ed. Costa Rica, San José, 1979. 